TITLE:

\title{
Multi-color persistent luminescence in transparent glass ceramics containing spinel nano-crystals with $\mathrm{Mn}[2+]$ ions
}

\section{AUTHOR(S):}

Zhuang, Yixi; Ueda, Jumpei; Tanabe, Setsuhisa

\section{CITATION:}

Zhuang, Yixi ... [et al]. Multi-color persistent luminescence in transparent glass ceramics containing spinel nano-crystals with Mn[2+] ions. Applied Physics Letters 2014, 105(19): 191904.

ISSUE DATE:

2014-11-10

URL:

http://hdl.handle.net/2433/192477

\section{RIGHT:}

Copyright 2014 American Institute of Physics. This article may be downloaded for personal use only. Any other use requires prior permission of the author and the American Institute of Physics. 


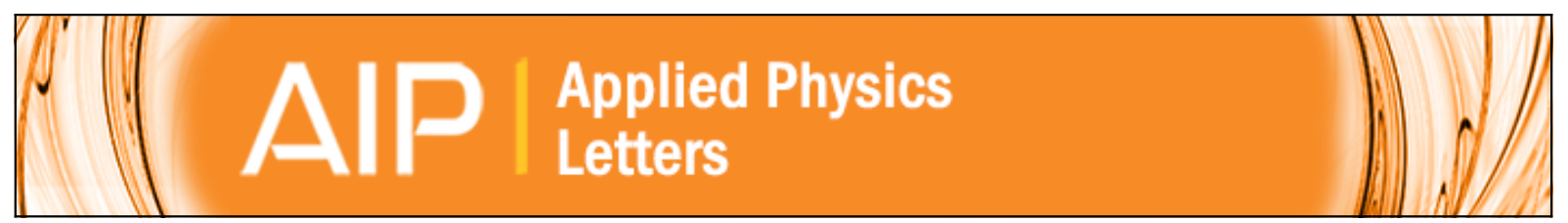

\section{Multi-color persistent luminescence in transparent glass ceramics containing spinel nano-crystals with $\mathbf{M n 2 +}$ ions}

Yixi Zhuang, Jumpei Ueda, and Setsuhisa Tanabe

Citation: Applied Physics Letters 105, 191904 (2014); doi: 10.1063/1.4901749

View online: http://dx.doi.org/10.1063/1.4901749

View Table of Contents: http://scitation.aip.org/content/aip/journal/apl/105/19?ver=pdfcov

Published by the AIP Publishing

\section{Articles you may be interested in}

Broadband optical amplification in silicate glass ceramics containing Li 2 ZnSiO 4 : Cr 4 + nanocrystals

Appl. Phys. Lett. 95, 111913 (2009); 10.1063/1.3231439

Optical spectroscopy of Eu $3+$ and Tb 3 + doped glass ceramics containing LiYbF 4 nanocrystals Appl. Phys. Lett. 94, 041909 (2009); 10.1063/1.3076111

Enhanced broadband near-infrared luminescence in transparent silicate glass ceramics containing Yb $3+$ ions and Ni $2+$-doped Li Ga 5 O 8 nanocrystals

Appl. Phys. Lett. 92, 041110 (2008); 10.1063/1.2839333

Intense ultraviolet emission from Tb $3+$ and $\mathrm{Yb} 3+$ codoped glass ceramic containing Ca $\mathrm{F} 2$ nanocrystals Appl. Phys. Lett. 90, 131116 (2007); 10.1063/1.2719028

Judd-Ofelt analysis and luminescence behavior of $\mathrm{Er} 3+$ ions in glass ceramics containing $\mathrm{Sr} F 2$ nanocrystals J. Appl. Phys. 99, 074302 (2006); 10.1063/1.2189021

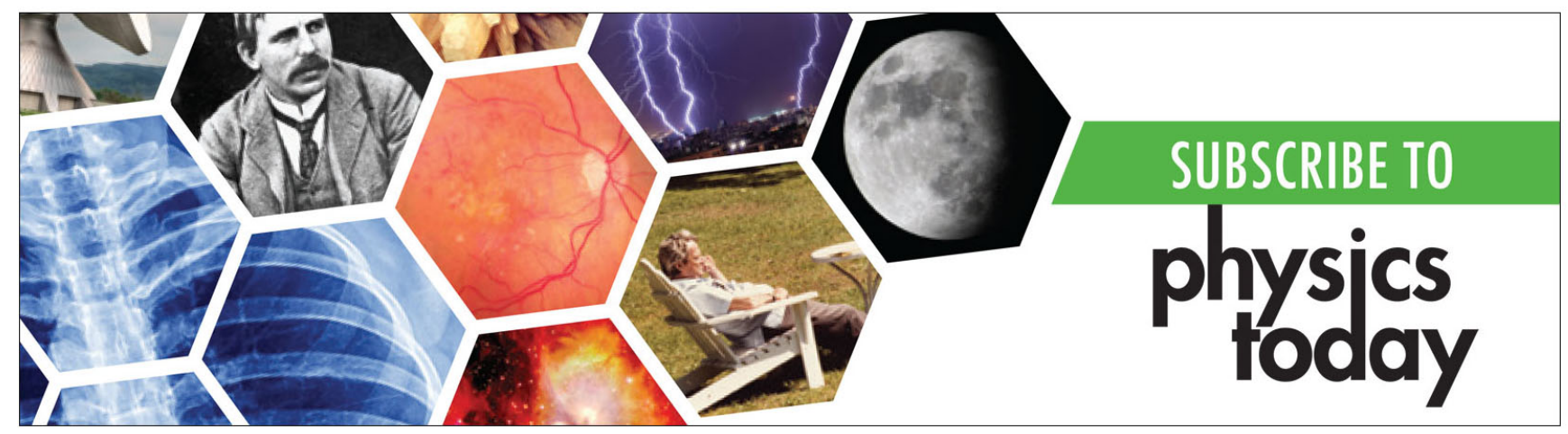




\title{
Multi-color persistent luminescence in transparent glass ceramics containing spinel nano-crystals with $\mathrm{Mn}^{2+}$ ions
}

\author{
Yixi Zhuang, ${ }^{1,2, a)}$ Jumpei Ueda, ${ }^{1}$ and Setsuhisa Tanabe ${ }^{1}$ \\ ${ }^{1}$ Graduate School of Human and Environmental Studies, Kyoto University, Kyoto 606-8501, Japan \\ ${ }^{2}$ College of Materials, Xiamen University, Xiamen 361005, China
}

(Received 8 October 2014; accepted 3 November 2014; published online 12 November 2014)

\begin{abstract}
Transparent inorganic materials showing persistent luminescence can act as cover layer and emergency lighting for security signs in the dark. Herein, we report a $\mathrm{Mn}^{2+}$-activated glass and transparent glass ceramics containing spinel-type $\mathrm{Zn}_{1+\mathrm{x}} \mathrm{Ga}_{2-2 \mathrm{x}} \mathrm{Ge}_{\mathrm{x}} \mathrm{O}_{4}(0 \leq \mathrm{x} \leq 1)$ nano-crystals, which show multi-color persistent luminescence for more than $10 \mathrm{~min}$. The color of persistent luminescence showed a remarkable change from red, to orange, greenish, and green with respect to the increase of annealing temperature. The effect has been explained due to the variation of crystal field strength surrounding the $\mathrm{Mn}^{2+}$ ions. (C) 2014 AIP Publishing LLC.
\end{abstract}

[http://dx.doi.org/10.1063/1.4901749]

Transparent inorganic materials have found extensive application in many important optical devices, including high-energy lasers, ${ }^{1,2}$ scintillators, ${ }^{3,4}$ and optical fiber amplifiers. ${ }^{5,6}$ One of the major advantages of transparent materials compared to other inorganic materials is their high ability to transmit light through the body. On the other hand, these transparent inorganic materials show additional functions in optical properties for specific applications. ${ }^{7-9}$ For example, single crystals used for gamma ray scintillators $\left(\mathrm{Gd}_{2} \mathrm{SiO}_{5}\right.$ : $\mathrm{Ce}^{3+}$ and $\mathrm{LaBr}_{3}: \mathrm{Ce}^{3+}$ ) require high light output, fast scintillation, as well as high transparency for efficient signal detection. In telecommunication system, optical fiber amplifiers $\left(\mathrm{Er}^{3+}\right.$-doped silicate glass) show low loss (transparent in the telecommunication window) and large gain (optical amplification) for long-distance signal transmission.

The application of transparent materials will be extended to more fields if other optical functions are provided by the transparent body. A cover glass works as a protective layer, as usual, without blocking readable messages under the glass (character "A" and line "_-" in Fig. 1(a)), when it is placed under a white fluorescent lamp. If this cover glass shows ability to give out light even after the lamp is turn off (i.e., showing persistent luminescence), the messages under the cover glass are still readable in the dark, as shown in Fig. 1(b). The transparent materials showing persistent luminescence, which are functionalized as protective layer and emergency lighting may find applications for night-vision illumination and indication, e.g., in face cover of watch, front panel of electronic device, and top layer of security sign. ${ }^{10,11}$

Persistent luminescence is a well known phenomenon that materials give out light (i.e., emit visible photons) for seconds, minutes, and even hours after the excitation sources are totally removed. In physics of phosphor materials, persistent luminescence is a kind of thermoluminescence at a certain temperature (usually referred to room temperature), in which electrons or holes captured by traps are released by thermal energy in a slow rate, return to active center, and

a)E-mail: zhuangyixi@xmu.edu.cn emit visible photons. ${ }^{12-15}$ Due to their large potential in glow-in-the-dark applications, great efforts have been paid to develop new materials showing persistent luminescence since the end of last century. Those efforts have brought out a big list of excellent persistent phosphors, including the famous $\mathrm{CaAl}_{2} \mathrm{O}_{4}: \mathrm{Eu}^{2+}, \mathrm{Nd}^{3+}$ (blue), ${ }^{16} \mathrm{SrAl}_{2} \mathrm{O}_{4}: \mathrm{Eu}^{2+}, \mathrm{Dy}^{3+}$ (green), ${ }^{17,18} \mathrm{Gd}_{3} \mathrm{Al}_{2} \mathrm{Ga}_{3} \mathrm{O}_{12}: \mathrm{Ce}^{3+}, \mathrm{Cr}^{3+}$ (yellow), ${ }^{19}$ and $\mathrm{Y}_{2} \mathrm{O}_{2} \mathrm{~S}: \mathrm{Eu}^{3+}, \mathrm{Mg}^{2+}, \mathrm{Ti}^{4+}$ (red) phosphors. ${ }^{20}$ However, almost reported materials showing persistent luminescence are polycrystalline powders in the size scale of micrometers. Commonly, these polycrystalline powders have to be made into paint or ink and brushed in specific characters or images with poor resolution, in order to deliver readable message in dark environments. ${ }^{21}$ If persistent luminescence can be obtained in a transparent body, the transparent material can be packaged or laminated on the top of security signs or other images, as shown in Fig. 1. The materials showing both persistent luminescence and high transparency may greatly expand the range of their applications.

In this article, we give an example of transparent materials based on a single germanate glass and transparent glass

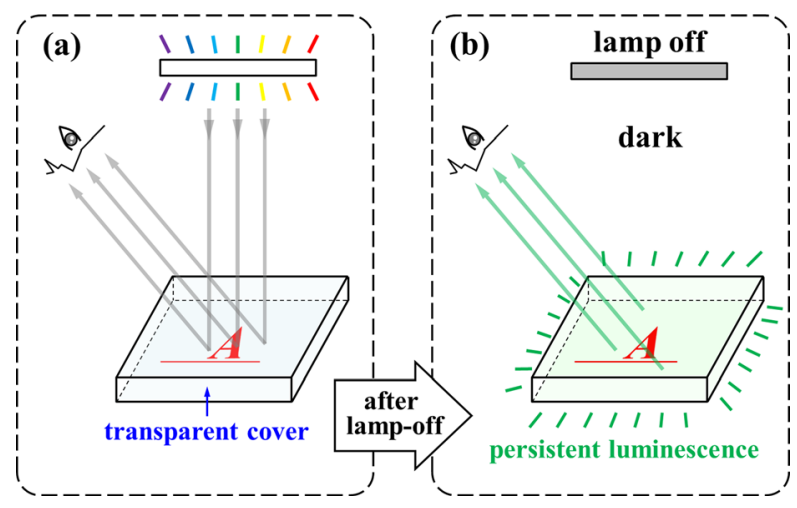

FIG. 1. Application of transparent materials showing persistent luminescence: to visualize message under the cover (character " $A$ " and line "- ") in the dark. (a) Under a white fluorescent lamp, the transparent cover works as a protective layer without blocking written message. (b) When the lamp is off, the transparent cover also works as emergency lighting. The message under the transparent cover is still readable in the dark. 
ceramics from the same glass with post-heat-treatment, which show multi-color persistent luminescence from red, to orange, greenish, and green. These materials can be potentially used as cover layer in the glow-in-the-dark applications.

Precursor glasses were prepared by a conventional meltquenching method. Raw material powder with nominal composition of $20 \mathrm{ZnO}-10 \mathrm{Ga}_{2} \mathrm{O}_{3}-64 \mathrm{GeO}_{2}-4 \mathrm{~K}_{2} \mathrm{CO}_{3}-1 \mathrm{Al}_{2} \mathrm{O}_{3}$ $-2 \mathrm{Al}-0.1 \mathrm{MnCO}_{3}$ (in mol. \%) was melted in a covered alumina crucible at $1525^{\circ} \mathrm{C}$ for $30 \mathrm{~min}$. Then the melt was poured and quenched on a stainless-steel plate preheated to $200^{\circ} \mathrm{C}$. The as-made glass was notated as AG. Some pieces of $\mathrm{AG}$ samples were further annealed at 650, 750, and $850{ }^{\circ} \mathrm{C}$ for $2 \mathrm{~h}$ under $\mathrm{N}_{2}$ flow to obtain glass ceramics (notated as GC650, GC750, and GC850, respectively). Al metal was used instead of $\mathrm{Al}_{2} \mathrm{O}_{3}$ as raw material and $\mathrm{N}_{2}$ flow in the annealing stage were supplied to make sure that $\mathrm{Mn}^{2+}$ ions dominated over other $\mathrm{Mn}$ ions of higher valence states in the AG and GC samples. Finally, the samples were cut into $12 \times 12 \times 1.8 \mathrm{~mm}^{3}$ sheets and double-face polished for optical measurements.

Crystal phases of the samples were identified by powder X-ray diffraction (XRD) measurement (Shimadzu, XRD6000). Transmittance spectra in the region of 200-1100 nm were obtained by using a UV-VIS-NIR spectrophotometer (Shimadzu, UV3600). Photoluminescence (PL) and persistent luminescence spectra were recorded by using a CCD detector (Ocean Optics, QE65 Pro). A Hg lamp (254 nm) was used as excitation source. Photographs of the samples were taken with a digital camera (Canon, EOS 5D Mark-II) in an all-manual mode.

XRD patterns of the AG and GC samples annealed at different temperatures are shown in Fig. 2. Only halos characterized by amorphous structure were observed in the AG sample; whereas additional diffraction peaks appeared in the three GC samples. The diffraction peaks were all indexed to cubic spinel-type $\mathrm{Zn}_{1+\mathrm{x}} \mathrm{Ga}_{2-2 \mathrm{x}} \mathrm{Ge}_{\mathrm{x}} \mathrm{O}_{4}(0 \leq \mathrm{x} \leq 1)$ crystals. However, the exact composition of the precipitated crystals (the value of $\mathrm{x}$ ) was difficult to obtain from the XRD results,

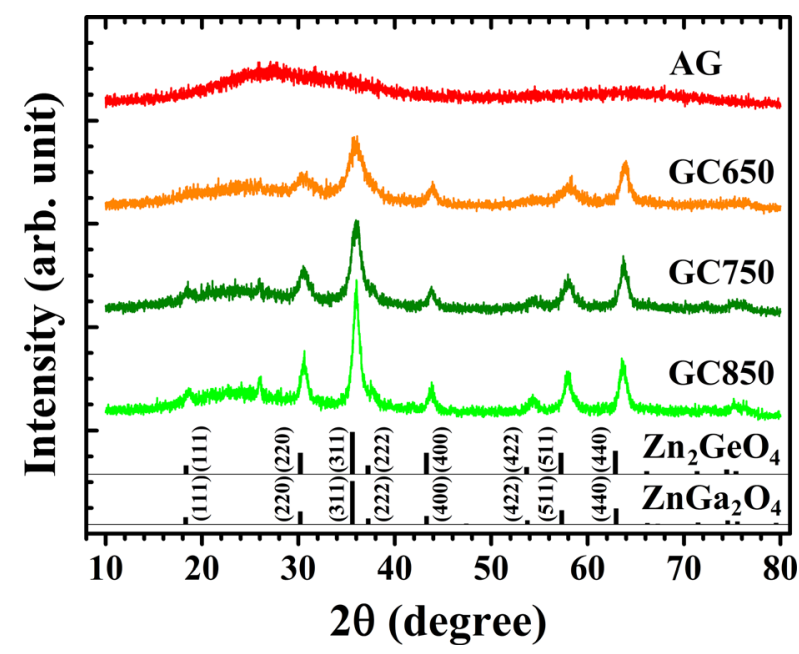

FIG. 2. XRD patterns of the AG, GC650, GC750, and GC850 samples. Reference data for two end-member of spinel-type $\mathrm{Zn}_{1+\mathrm{x}} \mathrm{Ga}_{2-2 \mathrm{x}} \mathrm{Ge}_{\mathrm{x}} \mathrm{O}_{4}$ solid solution $\left(\mathrm{ZnGa}_{2} \mathrm{O}_{4}\right.$ when $\mathrm{x}=0$, and $\mathrm{Zn}_{2} \mathrm{GeO}_{4}$ when $\left.\mathrm{x}=1\right)$ are given at the bottom. since two end-member of the $\mathrm{Zn}_{1+\mathrm{x}} \mathrm{Ga}_{2-2 \mathrm{x}} \mathrm{Ge}_{\mathrm{x}} \mathrm{O}_{4}$ solid solution $\left(\mathrm{ZnGa}_{2} \mathrm{O}_{4}\right.$ when $\mathrm{x}=0$, and $\mathrm{Zn}_{2} \mathrm{GeO}_{4}$ when $\left.\mathrm{x}=1\right)$ showed very similar diffraction patterns as given at the bottom of Fig. $2 .^{22}$ With increasing the annealing temperature, the diffraction intensity of these peaks increased and the full width at half maximum decreased, indicating growth of crystals at a higher temperature, which is similar to the XRD results in other transparent glass ceramics containing nano-sized fluorides. ${ }^{23-26}$ The sizes of $\mathrm{Zn}_{1+\mathrm{x}} \mathrm{Ga}_{2-2 \mathrm{x}} \mathrm{Ge}_{\mathrm{x}} \mathrm{O}_{4}$ $(0 \leq \mathrm{x} \leq 1)$ crystals estimated by Sherrer's equation were $4.9,8.1$, and $15.5 \mathrm{~nm}$ for the GC650, GC750, and GC850 samples, respectively.

Figure 3 shows photographs of the studied samples (from left to right: AG, GC650, GC750, and GC850), which were placed on a piece of white paper. In the presence of white light (top), the characters under the sheet samples could be clearly read, showing high transmittance in the visible region (approximately $75 \%$ at $550 \mathrm{~nm}$ according to their transmittance spectra). When exposed to $254 \mathrm{~nm}$ light (middle), the samples showed PL in different colors: red, orange, greenish, and green, from left to right. After the excitation lamp was removed (bottom), all the samples showed persistent luminescence, which could be observed by dark-adapted eyes for more than $10 \mathrm{~min}$. Due to the persistent luminescence, the characters under the samples could be well identified. On the other hand, the logo image left to the samples was totally dark. Notice that the color of persistent luminescence was similar to that of PL in each sample.

In order to investigate the variation of emission color, PL spectra of the samples were measured by using a CCD detector, as shown in Fig. 4(a). Under $254 \mathrm{~nm}$ excitation, the AG sample showed a single broad emission band with a maximum at about $630 \mathrm{~nm}$. In the GC samples, double emission bands peaked at about $520 \mathrm{~nm}$ and $650 \mathrm{~nm}$ were recorded. The relative intensity of $520 \mathrm{~nm}$ band increased while that of $650 \mathrm{~nm}$ band decreased in the GC sample annealed at a higher temperature.

All of the three emission bands in the PL spectra were attributed to ${ }^{4} \mathrm{~T}_{1}\left({ }^{4} \mathrm{G}\right) \rightarrow{ }^{6} \mathrm{~A}_{1}\left({ }^{6} \mathrm{~S}\right)$ electronic transition of

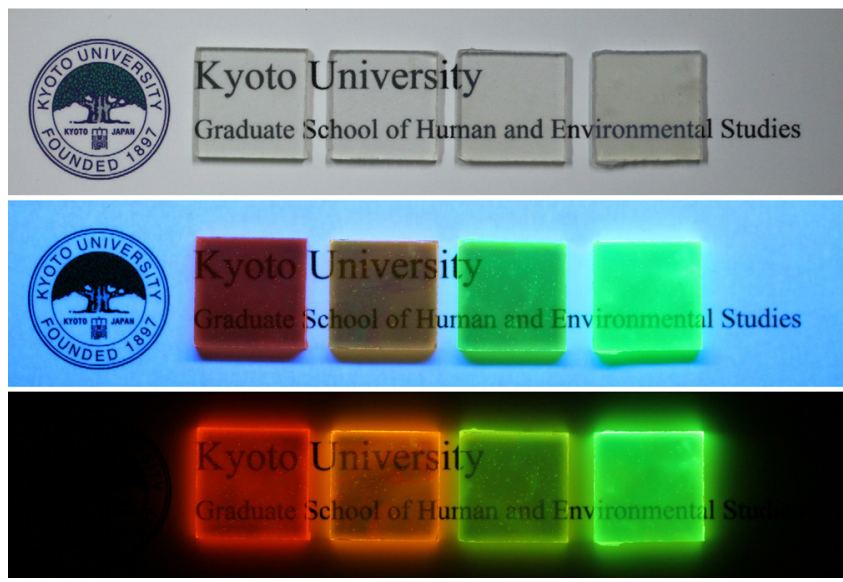

FIG. 3. Photographic images of the samples taken under white light (top), during $254 \mathrm{~nm}$ excitation (middle), and $5 \mathrm{~s}$ after $254 \mathrm{~nm}$ excitation (bottom). The samples from left to right in each picture are AG, GC650, GC750, and GC850. Exposure time was $1 / 500,1 / 125$, and $2 \mathrm{~s}$ for the top, middle, and bottom picture, respectively. Other parameters were manually kept constant: ISO value -1000 , aperture value -2.8 , and white balance-sunlight. 

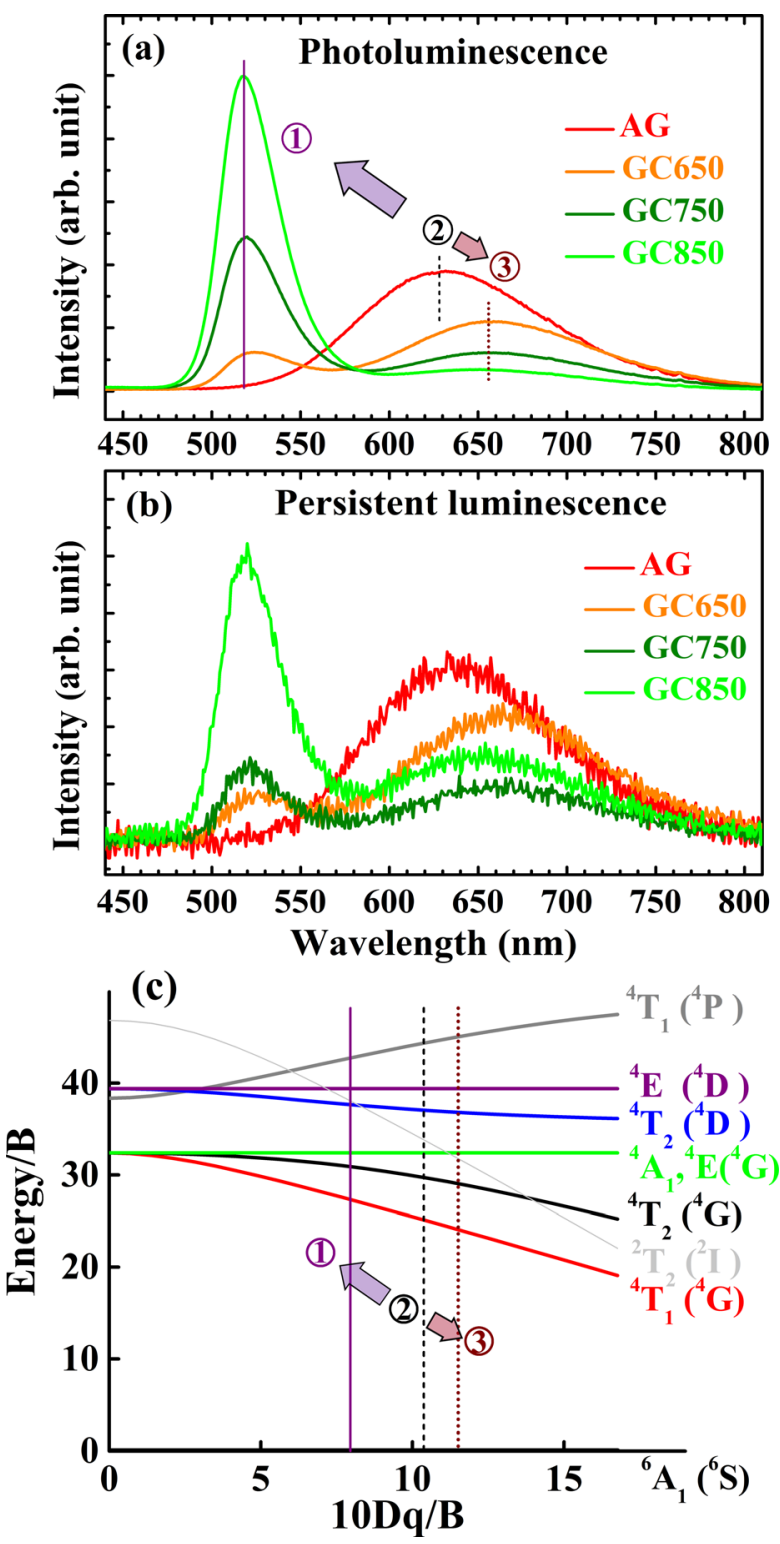

FIG. 4. PL spectra under $254 \mathrm{~nm}$ excitation (a) and persistent luminescence spectra $5 \mathrm{~s}$ after the same excitation (b) of the AG and GC samples. (c) Tanabe-Sugano diagram for $\mathrm{Mn}^{2+}$ ions with $3 \mathrm{~d}^{5}$ electronic configuration. The energy of excited states (in ordinate) varies with the increase of CFS surrounding the luminescent center (in abscissa). The CFS of $\mathrm{Mn}^{2+}$ ions incorporated in tetrahedral sites $(\Delta \mathrm{Td})$ is weaker than the CFS in octahedral sites ( $\Delta \mathrm{Oh}$, and theoretically $\Delta \mathrm{Td}=4 / 9 \times \Delta \mathrm{Oh})$.

$\mathrm{Mn}^{2+}$ ions. However, the emission energy is sensitively affected by the crystal field strength (CFS) surrounding the $\mathrm{Mn}^{2+}$ ions according to the Tanabe-Sugano diagram given in Fig. 4(c). ${ }^{27}$ The broad $630 \mathrm{~nm}$ (red) emission band in the AG sample is due to $\mathrm{Mn}^{2+}$ ions existing in glass phase with octahedral coordination (coordination number, $\mathrm{CN}=6$ ), which have been reported in some $\mathrm{Mn}^{2+}$-activated glasses. ${ }^{28}$ However, the $520 \mathrm{~nm}$ (green) band appearing in the GC samples is due to $\mathrm{Mn}^{2+}$ ions incorporated into tetrahedral sites $\left(\mathrm{Zn}^{\mathrm{IV}}\right.$ sites, $\left.\mathrm{CN}=4\right)$ in the precipitated $\mathrm{Zn}_{1+\mathrm{x}} \mathrm{Ga}_{2-2 \mathrm{x}} \mathrm{Ge}_{\mathrm{x}} \mathrm{O}_{4}$ $(0 \leq \mathrm{x} \leq 1)$ nano-crystals. ${ }^{29,30}$ According to the ligand theory, the CFS of $\mathrm{Mn}^{2+}$ ions in tetrahedral coordination is weaker than that in octahedral coordination. The reduction of CFS resulted in blue-shift of $\mathrm{Mn}^{2+}:{ }^{4} \mathrm{~T}_{1}\left({ }^{4} \mathrm{G}\right) \rightarrow{ }^{6} \mathrm{~A}_{1}\left({ }^{6} \mathrm{~S}\right)$ transition. ${ }^{31}$ On the other hand, the $650 \mathrm{~nm}$ (dark-red) emission band in GC samples is due to $\mathrm{Mn}^{2+}$ ions remaining in glass phase $(\mathrm{CN}=6)$. The red-shift of the ${ }^{4} \mathrm{~T}_{1}\left({ }^{4} \mathrm{G}\right) \rightarrow$ ${ }^{6} \mathrm{~A}_{1}\left({ }^{6} \mathrm{~S}\right)$ transition revealed that the $\mathrm{CFS}$ of $\mathrm{Mn}^{2+}$ ions increased after annealing. This effect could be originated from variation of composition (decease of $\mathrm{Zn}$ and $\mathrm{Ga}$ concentration) in the glass phase during the annealing process. ${ }^{32}$ Meanwhile, rise of the $520 \mathrm{~nm}$ band and quench of the $650 \mathrm{~nm}$ band in the PL spectra shows gradual migration of $\mathrm{Mn}^{2+}$ ions from glass phase to crystalline phase annealed at a higher temperature.

The persistent luminescence spectrum in Fig. 4(b) was similar to the PL spectrum for each sample, indicating that the same $\mathrm{Mn}^{2+}$ ions worked as active centers for the observed persistent luminescence. The color change of persistent luminescence was also due to the variation of CFS surrounding the $\mathrm{Mn}^{2+}$ ions.

The $\mathrm{Zn}_{1+\mathrm{x}} \mathrm{Ga}_{2-2 \mathrm{x}} \mathrm{Ge}_{\mathrm{x}} \mathrm{O}_{4}(0 \leq \mathrm{x} \leq 1)$ crystals have been reported as promising hosts for phosphors showing longlasting persistent luminescence activated by $\mathrm{Cr}^{3+}, \mathrm{Mn}^{2+}$, or $\mathrm{Bi}^{3+}$ ions. ${ }^{22,30,33-37}$ According to the earlier reports, anti-site defects (i.e., $\mathrm{Zn}_{\mathrm{Ga}}^{\prime}$ or $\mathrm{Ga}_{\mathrm{Zn}}$ ) in the crystals are considered to be effective traps for the observed persistent luminescence. In our glass and transparent glass ceramics containing $\mathrm{Zn}_{1+\mathrm{x}} \mathrm{Ga}_{2-2 \mathrm{x}} \mathrm{Ge}_{\mathrm{x}} \mathrm{O}_{4} \quad(0 \leq \mathrm{x} \leq 1)$ nano-crystals, the similar anti-site defects formed in the melt-quenching process and annealing process could be origin of the trap centers. However, further investigation is required in order to get a more clear explanation.

To sum up, we developed a $\mathrm{Mn}^{2+}$-activated glass and transparent glass ceramics containing $\mathrm{Zn}_{1+\mathrm{x}} \mathrm{Ga}_{2-2 \mathrm{x}} \mathrm{Ge}_{\mathrm{x}} \mathrm{O}_{4}$ $(0 \leq \mathrm{x} \leq 1)$ nano-particles. The AG and GC samples showed multi-color photoluminescence and persistent luminescence from red to orange, greenish, and green. The change of emission color is attributed to the variation of crystal field strength surrounding the $\mathrm{Mn}^{2+}$ ions during the annealing process. These materials showing both high transparency and persistent luminescence can be used as cover layer for glow-in-the-dark applications.

This work was financially supported by a Grant-in-aid for JSPS Fellows (No. 24-806) and a Grant-in-aid for Challenging Exploratory Research (25620184).

${ }^{1}$ U. Keller, Nature 424, 831 (2003).

${ }^{2}$ A. Ikesue and Y. L. Aung, Nat. Photonics 2, 721 (2008).

${ }^{3}$ K. Takagi and T. Fukazawa, Appl. Phys. Lett. 42, 43 (1983).

${ }^{4}$ E. V. D. van Loef, P. Dorenbos, C. W. E. van Eijk, K. Krämer, and H. U. Güdel, Appl. Phys. Lett. 79, 1573 (2001).

${ }^{5}$ S. Tanabe, C.R. Chim. 5, 815 (2002).

${ }^{6}$ S.Tanabe, J. NonCryst. Solids 259, 1 (1999).

${ }^{7}$ S. Chenu, E. Véron, C. Genevois, G. Matzen, T. Cardinal, A. Etienne, D. Massiot, and M. Allix, Adv. Opt. Mater. 2, 364 (2014).

${ }^{8}$ S. Zhou, N. Jiang, K. Miura, S. Tanabe, M. Shimizu, M. Sakakura, Y. Shimotsuma, M. Nishi, J. Qiu, and K. Hirao, J. Am. Chem. Soc. 132, 17945 (2010).

${ }^{9}$ S. Zhou, N. Jiang, B. Wu, J. Hao, and J. Qiu, Adv. Funct. Mater. 19, 2081 (2009).

${ }^{10}$ S. Hirata, K. Totani, H. Kaji, M. Vacha, T. Watanabe, and C. Adachi, Adv. Opt. Mater. 1, 438 (2013).

${ }^{11}$ T. Nakanishi, Y. Katayama, J. Ueda, T. Honma, S. Tanabe, and T. Komatsu, J. Ceram. Soc. Jpn. 119, 609 (2011).

${ }^{12}$ H. F. Brito, J. Hölsä, T. Laamanen, M. Lastusaari, M. Malkamäki, and L. C. V. Rodrigues, Opt. Mater. Express 2, 371 (2012).

${ }^{13}$ K. Van den Eechout, P. F. Smet, and D. Poelman, Materials 3, 2536 (2010). 
${ }^{14}$ Y. Zhuang, Y. Katayama, J. Ueda, and S. Tanabe, Opt. Mater. 36, 1907 (2014).

${ }^{15}$ J. Ueda, K. Kuroishi, and S. Tanabe, Appl. Phys. Lett. 104, 101904 (2014).

${ }^{16}$ T. Aitasalo, J. Hölsa, H. Jungner, M. Lastusaari, and J. Niittykoski, J. Phys. Chem. B 110, 4589 (2006).

${ }^{17}$ T. Matsuzawa, Y. Aoki, N. Takeuchi, and Y. Murayama, J. Electrochem. Soc. 143, 2670 (1996).

${ }^{18}$ J. Ueda, T. Nakanishi, Y. Katayama, and S. Tanabe, Phys. Status Solidi C 9, $2322(2012)$

${ }^{19}$ J. Ueda, K. Kuroishi, and S. Tanabe, Appl. Phys. Express 7, 062201 (2014).

${ }^{20}$ Y. Wang and Z. Wang, J. Rare Earths 24, 25 (2006).

${ }^{21}$ J. Hölsa, Electrochem. Soc. Interface 18, 42-45 (2009).

${ }^{22}$ M. Allix, S. Chenu, E. Véron, T. Poumeyrol, E. A. Kouadri-Boudjelthia, S. Alahrache', F. Porcher, D. Massiot, and F. Fayon, Chem. Mater. 25, 1600 (2013).

${ }^{23}$ S. Tanabe, H. Hayashi, and T. Hanada, J. Am. Ceram. Soc. 85, 839 (2002).
${ }^{24}$ S. Tanabe, H. Hayashi, T. Hanada, and N. Onodera, Opt. Mater. 19, 343 (2002).

${ }^{25}$ Y. Kishi and S. Tanabe, J. Am. Ceram. Soc. 88, 3423 (2005).

${ }^{26}$ T. Murakami and S. Tanabe, J. Ceram. Soc. Jpn. 115, 605 (2007).

${ }^{27}$ Y. Tanabe and S. Sugano, J. Phys. Soc. Jpn. 9, 766 (1954).

${ }^{28}$ C. Li, Y. Yu, S. Wang, and Q. Su, J. Non-Cryst. Solids 321, 191 (2003).

${ }^{29}$ J. Qiu, H. Igarashi, and A. Makishima, Sci. Technol. Adv. Mater. 6, 431 (2005).

${ }^{30}$ K. Uheda, T. Maruyama, H. Takizawa, and T. Endo, J. Alloy. Compd. 262-263, 60 (1997).

${ }^{31}$ C. Li, Q. Su, and S. Wang, Mater. Res. Bull. 37, 1443 (2002).

${ }^{32}$ M. Kawano, H. Takebe, and M. Kuwabara, Opt. Mater. 32, 277 (2009).

${ }^{33}$ A. Bessière, S. Jacquart, K. Priolkar, A. Lecointre, B. Viana, and D. Gourier, Opt. Express 19, 10131 (2011).

${ }^{34}$ Z. Pan, Y. Lu, and F. Liu, Nat. Mater. 11, 58 (2012).

${ }^{35}$ Y. Zhuang, J. Ueda, and S. Tanabe, J. Mater. Chem. C 1, 7849 (2013).

${ }^{36}$ Y. Zhuang, J. Ueda, S. Tanabe, and P. Dorenbos, J. Mater. Chem. C 2, $5502(2014)$

${ }^{37}$ Y. Zhuang, J. Ueda, and S. Tanabe, Opt. Mater. Express 2, 1378 (2012). 